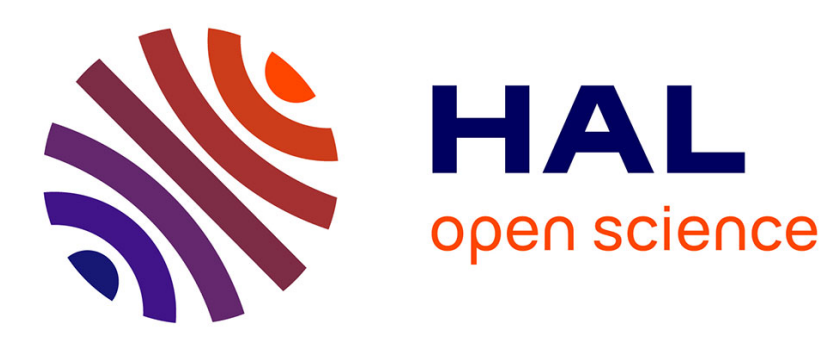

\title{
Potential optimization for the calculation of shocked liquid nitromethane properties
}

\author{
Nicolas Desbiens, Emeric Bourasseau, Jean-Bernard Maillet
}

\section{To cite this version:}

Nicolas Desbiens, Emeric Bourasseau, Jean-Bernard Maillet. Potential optimization for the calculation of shocked liquid nitromethane properties. Molecular Simulation, 2007, 33 (13), pp.1061-1070. 10.1080/08927020701589245 . hal-00515017

\section{HAL Id: hal-00515017 \\ https://hal.science/hal-00515017}

Submitted on 4 Sep 2010

HAL is a multi-disciplinary open access archive for the deposit and dissemination of scientific research documents, whether they are published or not. The documents may come from teaching and research institutions in France or abroad, or from public or private research centers.
L'archive ouverte pluridisciplinaire HAL, est destinée au dépôt et à la diffusion de documents scientifiques de niveau recherche, publiés ou non, émanant des établissements d'enseignement et de recherche français ou étrangers, des laboratoires publics ou privés. 


\section{Molecular Simulation}

Journal of

Experimental Nanoscience

- Taylor \& Francis

\section{Potential optimization for the calculation of shocked liquid nitromethane properties}

\begin{tabular}{|c|c|}
\hline Journal: & Molecular Simulation/Journal of Experimental Nanoscience \\
\hline Manuscript ID: & GMOS-2007-0056.R1 \\
\hline Journal: & Molecular Simulation \\
\hline $\begin{array}{l}\text { Date Submitted by the } \\
\text { Author: }\end{array}$ & 22-Jun-2007 \\
\hline Complete List of Authors: & $\begin{array}{l}\text { Desbiens, Nicolas; CEA } \\
\text { Bourasseau, Emeric; CEA } \\
\text { Maillet, Jean-Bernard; CEA }\end{array}$ \\
\hline Keywords: & $\begin{array}{l}\text { parameter optimization, nitromethane, shock hugoniot, Monte Carlo } \\
\text { simulations }\end{array}$ \\
\hline \multicolumn{2}{|c|}{$\begin{array}{l}\text { Note: The following files were submitted by the author for peer review, but cannot be converted } \\
\text { to PDF. You must view these files (e.g. movies) online. }\end{array}$} \\
\hline $\begin{array}{l}\text { biblio.bib } \\
\text { introduction.tex } \\
\text { methods.tex } \\
\text { results.tex } \\
\text { conclusion.tex } \\
\text { phjcp_mod.bst }\end{array}$ & \\
\hline
\end{tabular}

\section{SCHOLARONE \\ Manuscripts}




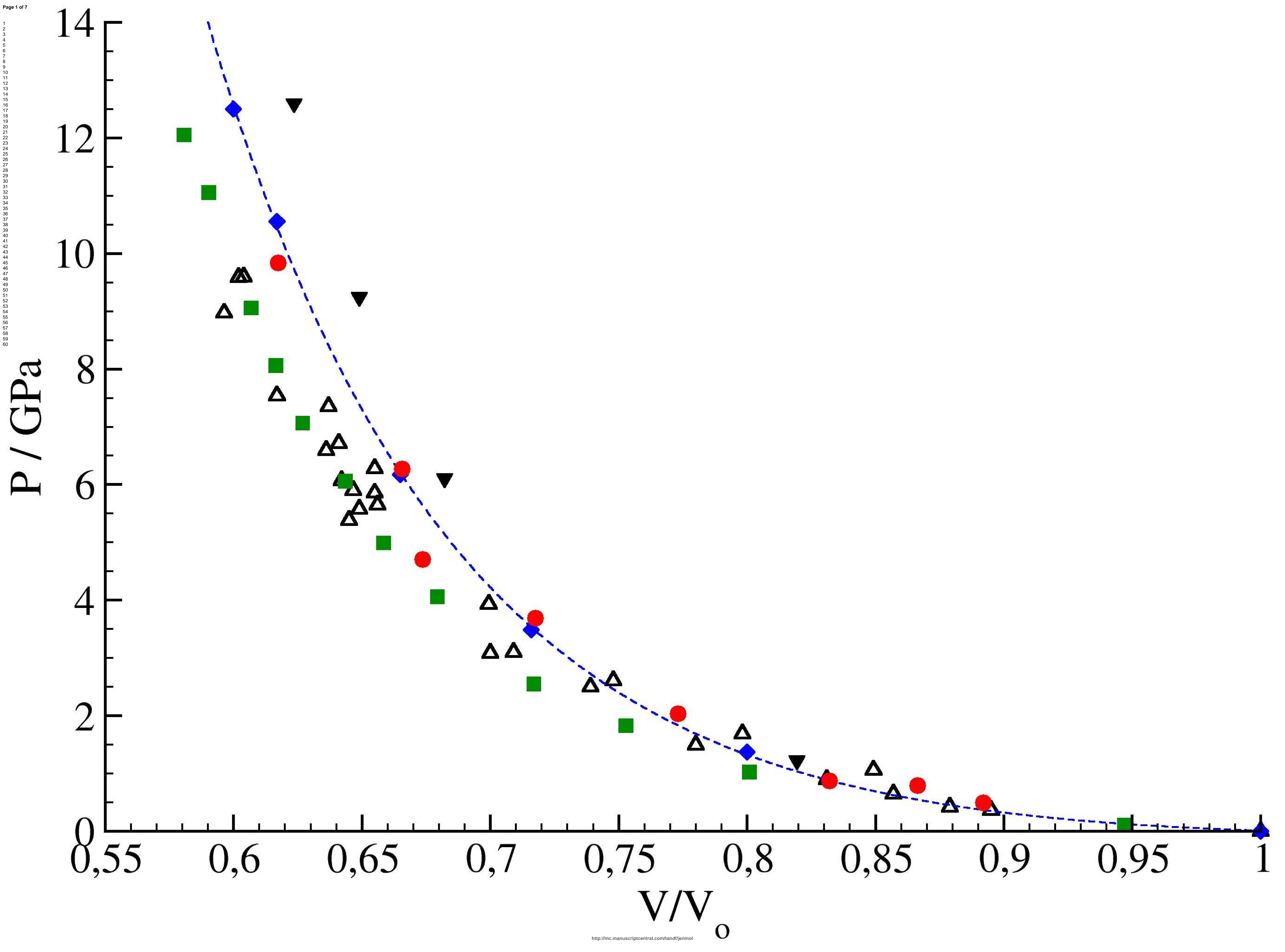




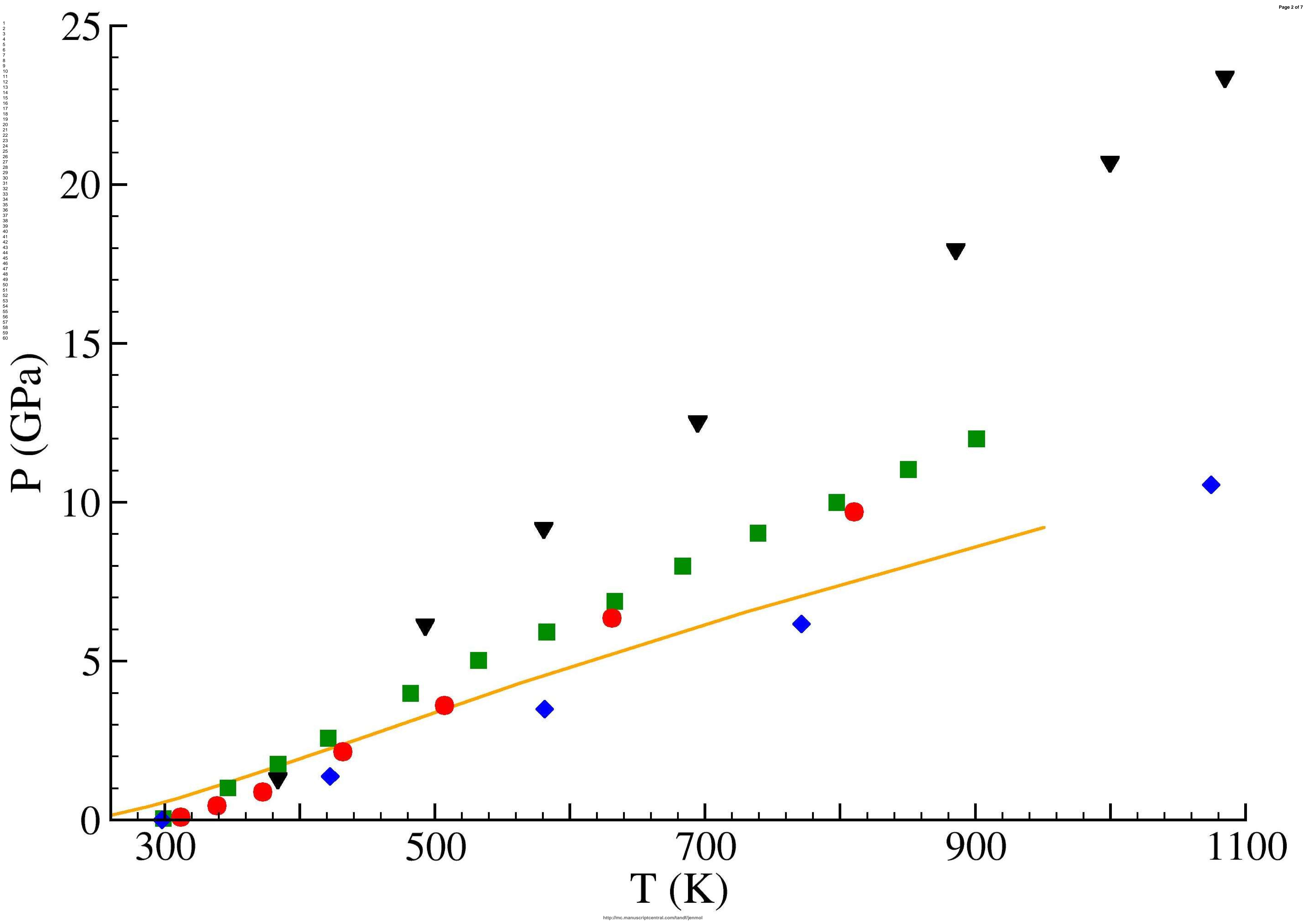




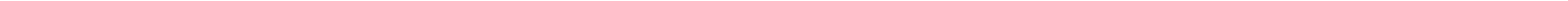




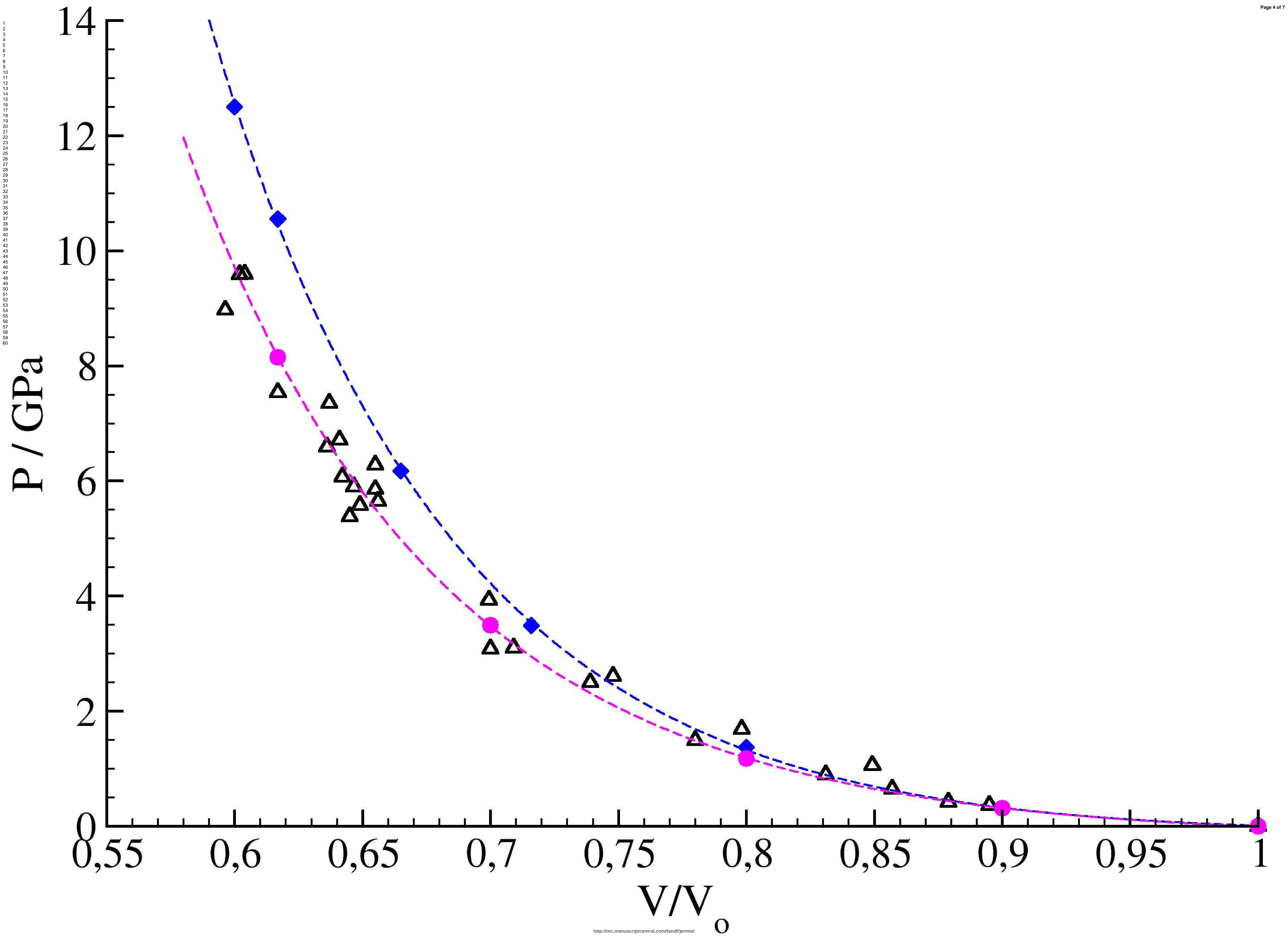




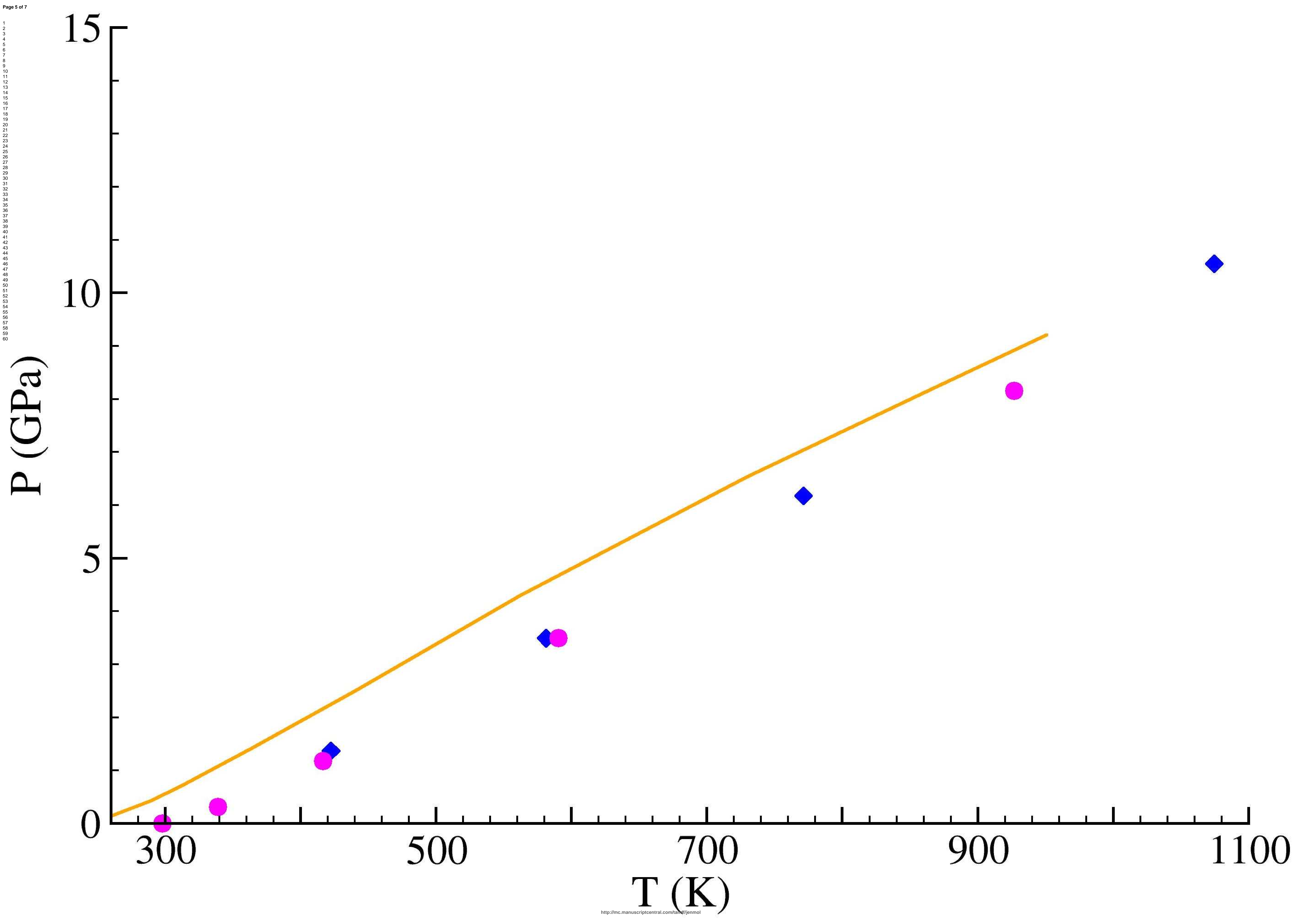




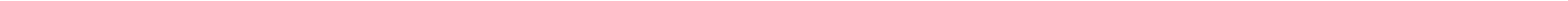




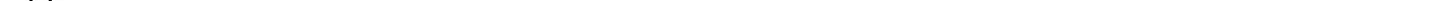

